KMC/Lifelong/9805/CompEd

\title{
From TRAINING TO EDUCATION Lifelong Learning in China
}

Cheng Kai-ming, Jin Xinhuo, Gu Xiaobo ${ }^{1}$

May 1998

Paper prepared for Comparative Education

${ }^{1}$ Kai-ming Cheng is Professor and Chair of Education, Pro-Vice-Chancellor at the University of Hong Kong. Jin Xinhuo and Guxiaobo are Researchers at the Shanghai Institute for Research in Adult Education, which is part of the Shanghai Academy for Educational Research. 


\section{Introduction}

Lifelong learning was nothing foreign in the Chinese tradition. There was no age limit for education in ancient China, although education in those days were mainly for examinations, which are the training ground for officials. A system of adult education was established in the 1950s, but that was to complement the formal education system as an instrument to implement state manpower planning. Lifelong education as a modern notion was introduced to China only by the end of the 1970s immediately after the Cultural Revolution. The notion did not gain much grounds when education was closely associated with state manpower plans and individuals did not have much room for personal development. The break away from strict manpower planning in the early 1980s has given rise to individual aspirations for education. Such aspirations have integrated with the long tradition of self-motivations in learning and have given rise to the spectacular expansion in all kinds of adult education. While the motives for such learning are still very much related to jobs and incomes, alternative objectives for learning are fast developing outside the formal sectors of education. This paper analyses the recent developments of life-long education in China, and uses Shanghai, the most developed city, as an example for illustration.

\section{A Strong Tradition of Education}

Education values in China was fostered by the civil examinations held at the imperial court. The civil examination system lasted for around 1300 years in ancient China until the turn of the 20th century. Such a tradition sets no limits to the modes and the age of learning. However, such a tradition also sets examination success as the end of learning. The interplay of such a tradition and the broad notion of lifelong education explains the recent developments.

Recent studies compare the civil examination system with the contemporary degree system in higher education. In ancient China, there was a clear distinction between "enlightenment" which was basic education for the mass and the civil examinations which were for adults. In both cases, they refer to literary learning. There were three levels of public examinations: county, provincial and national (imperial). There are strong arguments, with due research support, that the three levels were equivalent to Bachelors, Masters and Doctoral studies in modern education system (Liu, 1996: 217-227) .

Schools or institutions were not a necessity for success in the civil examination. Typically, self-motivated scholars studied the classics (Four Books and Five Classics) for long years at home before they attended the examination. 
Only a few studied in formal institutions established by the state. The role of such "schools" were not always favourably perceived and were indeed abolished at times (Ibid.: 139-206). In the system, which could be seen as the only education system in ancient China, examination and selection were the core. The mode of learning was never a central issue. In other words, it was an output-oriented or result-oriented system with practically no regard to the process. Indeed, most of the "heroes" in the folklore of scholars succeeded through self-study, often necessarily under very unfavourable life conditions.

The scholars were examined on their interpretation of the classics in relations to solving problems of the state. Such interpretations were fairly personal in nature, there were no standard answers, and normally there was no regular teacher during the study. Success in the civil examination was purely a recognition of the scholars' efforts and talents, not even a test of their knowledge or skills.

Pertinent to this paper is that study for the civil examination was a lifelong undertaking. Most of the scholars attempted repeated examinations and many of them were old in age when they succeeded. There were indeed awards to encourage elderly scholars, as a recognition of their unfailing will and effort to attempt the examination. The oldest candidate in record passed the examination at the age of 98! It was not unusual that candidates over a certain age (say 50) were given preferential treatments during the examination (Ibid.:209) There were cases where the Emperor granted honorary "degrees" to aged scholars, although some of them declined and regarded such as an insult to their academic integrity.

The civil examination provided an open access to a viable route to social mobility. The objective of civil examinations were purely for recruitment of government officers. There was therefore no built-in incentive for intrinsic motivation about knowledge and skills. However, there was extremely strong extrinsic motivation. Success in the civil examination often meant appointment to senior positions in the officialdom or even marriage with the royal family. However, there was no restriction on the candidature for the examination. It was a system of open access. The civil examination was the only route for social mobility, and such a route was seen to be applicable to all social classes. The open access to the examination has created a perceived "fairness" of the system, and that explains the survival of such a system over so many dynasties.

All in all, although individuals in ancient China regarded preparation for the civil examinations as serious "education", objectively, the system was little more than a training system for the officialdom.

Such social nature of the civil examination has brought with it the traditional values of education. Many of such values still prevail in contemporary societies. 
- Education is a matter of scholarship.

- Learning is understood as self-motivated and multi-modal.

- Learning has no age limit.

- Learning is for recognisable success which is often realised in examinations.

- The ultimate aim of learning is to become a member of the officialdom.

- There is little left for learning when one has accomplished in the examinations.

They work both for and against the development of life-long education. On the one hand, there is motivation for learning at any stage of life using any mode of learning. On the other hand, learning is for tangible success which is often related only to status and rewards.

\section{Adult Education in the Socialist System}

In the first years of the socialist Republic since 1949, China's followed closely the Russian system of education. With that came the sophisticated system of adult education which also explains the existing infrastructure of adult learning. To date the system of adult education in China comprises different integral parts as is shown in the following table.

Table 1: Adult Education in China

(Source: State Education Commission, 1998:2)

Institutions

Enrolment ('000)

Adult higher education

- Radio/TV Universities

- Workers' Colleges

- Peasant's Colleges

- Institutes for the Administrative Cadre

- Colleges of Education

- Independent Correspondence Colleges

- Attachments to formal institutions

- Correspondence Divisions

- Evening Schools

- Short-cycle courses for adults

$2,724.50$

505.9

325.5

0.9

160.7

228.3

13.7

$1,489.5$

903.2

344.5

241.8

$61,195.9$

Adult secondary education

731.3

532.0

- General Secondary Schools for Peasants

Specialised (Vocational) Secondary Schools for Adults

- Radio/TV Specialised Secondary Schools

702.4

- Specialised Secondary Schools for Staff and Workers 
- Specialised Secondary Schools for Cadres 152.5

- Specialised Secondary Schools for Peasants 224.9

- Correspondence Specialised Secondary Schools 219.7

- In-service Teacher Training Schools 443.6

Technical Training Schools for Adults

- Technical Training Schools for Staff and Workers

3.862 .2

- Technical Training Schools for Peasants

$57,268.8$

Adult Primary Schools

$6,160.6$

- Worker Primary Schools

151.3

- Peasant Primary Schools

$6,009.3$

Literacy Programmes (Often included in adult primary schools)

$3,530.0$

Total

$70,081.0$

The table only presents the traditional sectors of adult education. Other programmes, formal or nonformal, in such as continuous education, community education, education for the elderly, self-study examinations, which are newcomers in the scene and are more relevant to lifelong education, are not represented in the table. We will visit these aspects later in the paper.

Such an adult education system operates throughout the different levels of education: literacy programmes, primary and secondary schooling, higher education, teacher training and cadre upgrading. The system infiltrates all sectors of the work force. Adult study is commonplace in almost all families. The enrolments figures in the may give readers a crude idea of the scale.

There was also no lack of variety in the mode of learning. In adult higher education alone, the modes of learning include: radio and television broadcasts, evening face-to-face classes, correspondence courses, sabbatical programmes, day-release programmes, and others. All these have provided a very strong infrastructure for adult education in China.

Under the socialist system of planned economy, education was necessarily an essential part of manpower planning. Adult education was no exception. Adult education in the planned economy was not meant to be a second route for individuals' upgrading and upward mobility. Under the ideology of those days, there should be no personal interests beyond the state's interests, and there was indeed no room for personal mobility beyond the state plans. Rather, adult education had two aims: either to upgrade the literacy standard of the workers and peasants, the "proletariat", who had been deprived of education in the "old society", or to supplement the formal education system to prepare and re-train manpower for economic production and political leadership. 
Therefore, the adult education system was well planned by the state. The adult education providers are not very different from other educational institutions in their observation of state plans. Each institution was given an enrolment quota, provided resources therefor, and was given the staff accordingly.

The curriculum of adult education was not very different from the formal sector. For example, although there were separate syllabuses and textbooks for adult higher education, they were almost identical in contents, except that they were arranged according to a different time-frame and with different practical requirements. Hence, the adult higher education curriculum inherited all the rigidity and sometimes obsolescence of the formal curriculum. The curriculum was rigidly associated with narrow jobs in the workplace.

As part of manpower planning, enrolments were controlled by an Adult Higher Education Entrance Examination which was the threshold for adult higher education admissions. The threshold was norm-referenced and was adjustable according to the planned intake quota. Such a system is still in place, although it faces enormous pressure for a change

In the same context, there was no open access to adult higher education. Before the reform, a potential candidate who aspired to do adult education had to seek approval and recommendation from the superior. The superior would approve and recommend only when the candidate fell within the work-unit's plans. There was no honour for individual aspirations. However, once the person was approved, there would be full facility for study leave, allotted time for television watching and self study, and all kinds of release from work.

In this consistent concept of adult education oriented by state plan, not only that admissions were controlled as mentioned above, graduates of adult higher education were expected to change their posts only when it was part of the state plan. This was compatible with their counterparts in formal higher education, where graduates were assigned jobs according to the state plan. There was therefore little incentive for individuals to pursue adult education.

Graduates of adult higher education were not awarded degrees. Even before the reform when the degree system did not exist ${ }^{2}$, graduate from adult education never received a diploma which was equivalent to that for a four-year full university course. There was always a tight control of the scale of higher education as a matter of manpower planning. Adult education was not meant to undermine such a control of scale. Meanwhile, to date, graduates of adult higher education are only awarded non-degree diplomas. Unless in very exceptional cases, no degrees are awarded in adult higher education. The non-formal sector is subtly seen as second rate.

2 Degrees are introduced to the Chinese higher education system only in 1981. 
Hence, there has been a comprehensive infrastructure of adult education in general and adult higher education in particular. The contents and operation of the system, however, was heavy and inflexible. The old tradition for lifelong efforts of learning sustained, but the tradition of open access and individual motives were lost under the socialist ideology of manpower planning.

Hence, it is safe to say that during the years before the reform, lifelong learning took place in a relatively formal framework. Adult education was only supplementary to formal education as a vehicle to train adult manpower for the state.

\section{The Impact of the Market}

The reform in the larger context has caused changes in the adult education system. In the early 1980s, for the first time, the state allowed the operation of private enterprises, joint ventures with foreign investment and self-employment. All these gave rise to employment opportunities outside the state plan. Since, the job market, which was a new comer in the socialist economy, has ever expanded. Gradually, self-sought jobs have become preferred over jobs in state enterprises. In the late 1990s, there is even an active state policy to dismantle the state sector of the economy. Running the risk of facing huge unemployment, the state has determined to eliminate all together job assignment by the state. Job assignment will disappear for higher education graduates in 2000, but it has already disappeared for graduates of secondary technical and vocational schools.

The change in the status of state plans is also matched by the growth in personal incomes, hence giving individuals the resources necessary to pursue learning. Overall, there have been needs for new manpower in the market, and individuals could also afford to upgrade themselves in order to improve their employment situations in the market. All these which would be commonplace in any capitalist society are unprecedented in socialist China.

There is therefore a spectacular expansion of adult education in the past two decades. Figure 1 illustrates the trend in expansion in adult higher education which is the most significant part of adult education in China. 
Figure 1: Expansion of Adult Higher Education in China ${ }^{3}$

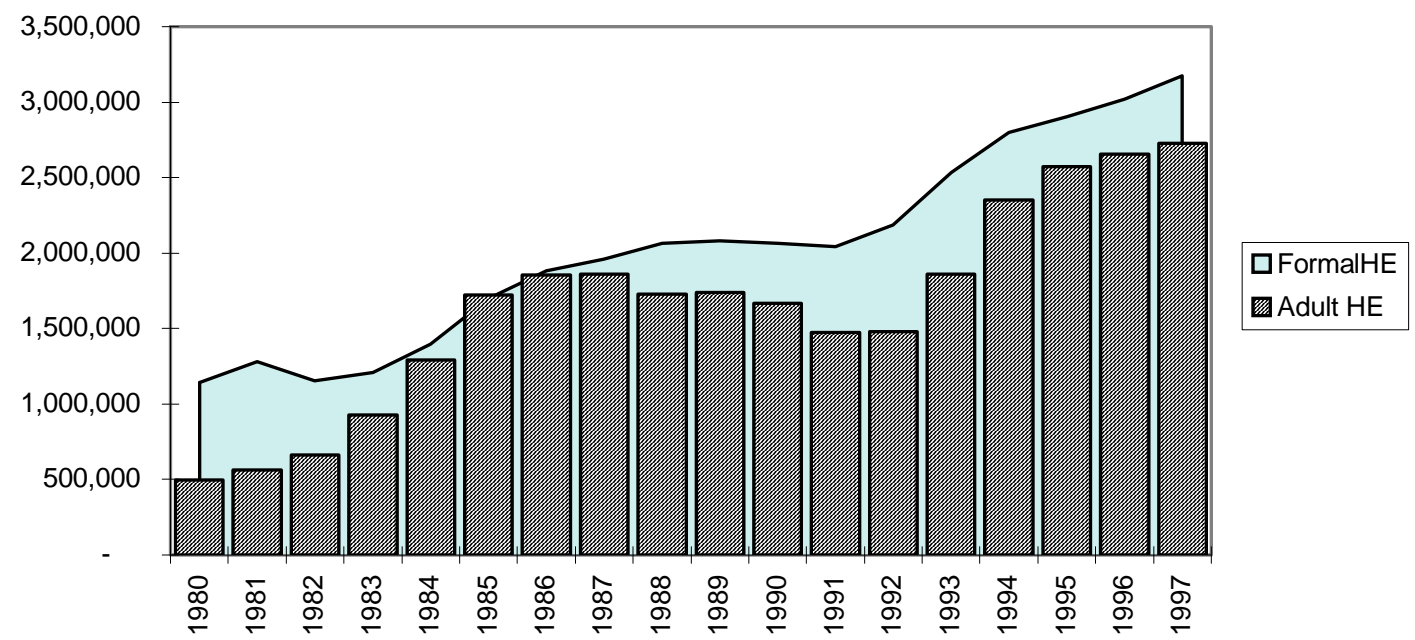

Overall, there is a very significant growth in enrolment in adult education programmes. In 1997, the total enrolment in adult higher education was over 2.7 million, almost comparable with the total enrolment in formal higher education, which was less than 3.2 million. The diagram also illustrates the ups and downs of the development in adult education, which reflects that the change from a state manpower undertaking to an individual endeavour is by no means straightforward.

First, there was the issue of recommendation during admissions. When the job market first emerged, state employees who would like to apply for studies unrelated to their job assignments were seen as deviants. They were often not favourably supported and hence reluctantly recommended by their superiors. This was soon over when the job market further expanded and jobswitch became common. The influence was not significant in the actual growth of adult education enrolments.

Second, the supply of adult education was curtailed by state planning. In 1988, the state, for the first time, felt the challenge from adult education to stable job distribution. There was then a policy that adult education qualifications would not automatically warrant job promotion or job change. This served as a disincentive to adult education. There was therefore a drop in enrolment in 1988. There were further drops in the next three years, very much because of the readjustment (known as "macro co-ordination") in the economy and the jobmarket was very unstable.

\footnotetext{
${ }^{3}$ Source: State Education Commission, 1998: 1-2; 1997:339, 345; 1991:5, 87; 1986:4, 95; 1984:22,
} 239. 
Third, thereafter, adult education was ever expanding. This was partly a result of the expansion of the job market, but partly it is also because of the policy of limiting the scale of formal higher education. The expansion in adult higher education has also been contained by policies which do not favour massive expansion in higher education. The expansion is also offset by the decline in quality in some of the institutions, which has led to government intervention in the expansion of adult education.

After all, there is still the artificial discrimination between formal and adult education. To date, formal and adult higher education operate under different divisions of the Ministry of Education ${ }^{4}$. Adult education institutions are not allowed to mount four-year degree programmes. Only in exceptional cases could their graduates be awarded degrees conferred by a recognised institution. Even formal institutions which launch adult programmes have to abide by this rule. This has very much reduced the attractiveness of adult education programmes. This is particularly significant in large cities where degree holders are most wanted in the job market.

In sum, the market has given room and provided incentives for individual endeavours in adult education. The market has caused a collapse of the system of state-controlled and manpower-planned adult education. Such an endeavour, nonetheless, is very much driven by employment or incomes.

\section{The Changing Scene}

However, development in adult education is no longer accountable only by enrolments in adult education. Self-study Examinations, which has genuine open access, has provided the widest opportunity to adult learning.

Self-study Examination was started in 1981 (Liu, 1993:2016). Very much due to the uncertainty about the economic changes and the future of job-market, it did not make very spectacular impact in the first years. Into the 1990s, Selfstudy Examinations have become the major thrust in adult learning in China.

Self-study Examinations operate on open admissions. Any citizen can register for the Self-Study Examination. There is no age limit and no academic qualification requirements for the candidates (State Council, 1988). The examination syllabuses are publicly accessible. Candidates may sit for single subjects. They may then accumulate their results over years and receive certification for higher education graduation. Typically, for preparation, candidates attend paid courses that are tailor-made for the Examinations. Such course are offered either by private institutions or by established institutions as a way of income generation.

\footnotetext{
${ }^{4}$ Formerly the State Education Commission; renamed Ministry of Education in April ,1998.
} 
Registration for Self-study Examination takes place twice a year. In 1995, the spring enrolment was 3.6 million, which is more than the total population in the formal sector of higher education.

Since there is no institutional attachment to Self-study Examination, it provides adults with a true open access to higher education. It bypasses all bureaucratic barriers as well as academic preconditions. It therefore provides a real "second chance" for those who were not so successful in the formal education system.

The test of the pudding is in the eating. The real test for the Self-study Examination is its acceptance by the market. Under the new circumstances, the state has no commitment to the appointment of those who have attained formal qualification from the Self-study Examinations. It is up to the graduates to demonstrate their values to the potential employers.

If Self-study Examinations are a liberal sector on the side of the education system, then liberalisation in the formal sector is even more dramatic. Since 1997, all universities in China have started charging student fees. Meanwhile, plans are being implemented such that in 2000, graduate job-assignments will be totally abolished. In other words, then, university students will be forced to view higher education as a private investment. They have to calculate the returns to investment in higher education, and to weigh their opportunities with their preferred career.

Such necessary individual calculations will inevitably further change people's perceptions of formal education, and will have enormous implications for adult education. For example, the reform in graduate employment will further reinforce the market elements in job-matching, and will shift employers' attentions from paper qualifications to the actual ability of graduates. This may give adult education more opportunities to compete with the formal sector on equal footing.

However, the most significant change is in the concept of lifelong learning which goes beyond academic qualification and employment. In 1987, a policy statement stipulated five major aims of adult education (State Education Commission, 1987):

- training for job-transfer or re-employment,

- remedial education for workers who dropped out of schools,

- compensatory training for incompetent workers,

- continuous education of the educated,

- enhancement of adult lives and culture.

The five aims did not include re-training of the unemployed, which has become a real need in the last years of the $20^{\text {th }}$ century. The last two aims have moved away from manpower considerations into the realm of lifelong learning in the 
genuine sense of the term. The following case of Shanghai may illustrate the scene.

\section{Continuous Education and Re-training}

Since the early 1990s, Shanghai has seen tremendous changes in the economy. This has raised new demands on the manpower. Such changes include structural changes in the economy, with a dramatic shift from manufacturing to service and financial industries. In the two decades from 1978 to 1997, the contribution of the tertiary sector to the economy changed from $18.6 \%$ to $45.5 \%$ (Jin and $\mathrm{Gu}, 1998: 1$ ). Job-specific training, which is more apt for manufacturing, has given way to broad-based general education which is expected by the tertiary industries. All these happened in a matter of years, among the same generation of the work force, thus forcing the adult workers to upgrade their educational qualifications. This is naturally done through all kinds of adult education.

The employment of guest workers has also replaced local people in manual labour and hence reduced the need for skills-training, in the narrow sense of the term, for local people. China has experienced one of the largest mobility of the working force in the past decade. There is a general pattern of young workers fled the rural field and from less developed provinces and work in urban centres as raw labour. The control of population shift, which was achieved effectively by food rationing, is no longer valid because food is now in the market. Shanghai has a concentration of such labourers. Official estimation indicates that around one-fifth of the work force in Shanghai are non-local (Ibid.:2). Such elements in the work force include raw labours employed in local factories, domestic helpers and construction teams from rural villages. The guest workers have generally raised the employment aspirations of local workers. Many of them turn to adult education in order to re-define their work status.

There is also a shift in the technological level required by the industries. Such changes have caused structural unemployment and re-deployment problems which are unprecedented in China. In 1997, technology-based industries have contributed to $52.3 \%$ of total industrial output. "High-tech" industries which involve electronics, biotechnology and material sciences have contributed to $15.1 \%$ of the industrial output (Ibid.:1). Adults in manual labour an in non-technological industries face the pressure of re-training in order to maintain the same incomes. They turn to adult education as an obvious solution.

The challenges were further exacerbated by the national policy of phasing out state enterprises, which has caused massive unemployment since the late 1990s. The campaign, which has been a national policy since the mid-1990s and were formally announced in 1998, is to further "marketise" the industries and services. Such state-owned enterprises are generally seen as inefficient. They 
are usually heavily subsidised by the state and often over-staffed. In this campaign, employees who had worked and lived in a rather "domesticated" socialist system are virtually removed from their positions, paid a fractional salary or one-off gratuity, and are asked to find their own jobs. In Shanghai, since the early 1990s, there has been an accumulated total of over one million workers who where laid-off by state enterprises, and an estimated 240,000, in 1997 , were awaiting jobs. It is estimated that $69 \%$ of these laid-off are in the 35-45 age group, and $72 \%$ are with education attainments before junior secondary (i.e. 9 years of formal education) (Ibid.: 2). This has posed tremendous pressure on retraining of the work force.

All these have posed new demand on education. Adult education naturally plays an essential role in coping with the changes. The developments of adult education in Shanghai takes several orientations, the major ones are onthe-job training and continuous education of the educated.

There is a trend towards institutionalising on-the-job in Shanghai (Ibid.:34). There is a general policy of integrating training, certification, deployment and remuneration in a comprehensive framework. The framework runs through pre-service, in-serve and job-transfer in relations to employment. Since 1992, all workers at foreman level in Shanghai have to undergo a licensing process before they are receive assignments. There is also a trend in various enterprises of introducing mandated hours for in-service training as part of the conditions of service. Many enterprises have established their own training departments, but increasingly more industries commission higher education or adult education institutions to mount contract training programmes for their appointees. Still others use public adult education qualifications as benchmarks for selections and promotions.

There is also an institutionalised emphasis on continuous education of the educated (Ibid.:4-5) . In 1993, Shanghai started a policy that requires all medium and high rank technical personnel to undergo no less than 72 hours of in-service off-job up-grading per year. The requirement for junior technical personnel is 42 hours per year. In most of the enterprises, there are integrated plans to upgrade the proficiency level of employees.

Overall, there is a shift in the nature and objectives of adult education. Instead of being used as a remedial measure in a static system, adult education has become an essential vehicle for proactively adapting the work force for rapid changes in the economy. In a way, adult education is one crucial factor that keeps Shanghai ahead of other place in all the changes in China.

\section{Non-qualification Education in Shanghai}


The need for lifelong education in Shanghai is very much prompted by changes in the larger context in the past two decades. Changed economic situations, changed demography and changed expectations of life quality have all created new aspirations for adult education.

First, there has been significant growth in the economy and hence in individual incomes. In the five year from 1992-1997, there has been an annual average of $7.2 \%$ growth in income of urban citizens (Ibid.:2). The relatively stable employment lives have given room for individuals to aspire for education beyond training for jobs and incomes. The reduced political instability and minimised political censorship for job assignments have all created the space for aspiration for genuine knowledge and leisure.

Second, the economic and political stability has provided people with the luxury to aspire for higher quality of lives and the consequent demand for better cultural lives. This further moves the desire for learning away from qualification-driven education. Quite unexpected by outsiders, the recent introduction of "double weekend" (i.e. designating both Saturdays and Sundays as non-working days) in 1996 has also contributed tremendously to the need for adult education. There used to be a life pattern of working six days and using the seventh day for housework. There is now new room for quality private lives.

Third, the shift in the demography to older ages has also reinforced such a need for education for quality life. In 1995, the population of 65 and above formed $11.8 \%$ of the constant population. This will be increased to $13 \%$ in 2000 (Ibid.:2). As a convention, people normally retire at the required age. Retirement lives are very much a matter of volunteer services and interests, and are often supported by adult education for the elderly.

Under these circumstances, there is significant shift of emphasis in adult education firstly from work-related training to personal developments, and secondly from pure leisure to self-development. There are largely two categories of programmes in such a development. The first category is life-related, such as cooking, gymnastics, clothing, beauty and home economics. The second category is more on humanities and art, such as dancing, musical instrument, drawing, calligraphy, philately, tea-art, and others. Both are known as nonqualification education.

Non-qualification educational programmes in Shanghai are mostly offered by non-government organisations. Such a special feature distinguishes nonqualification education from other types of education in two aspects. One, the programmes are financially supported mostly by the participants. Hence they reflect almost purely the social demand. Two, the programmes are almost totally detached from any government plan. Such programmes therefore enjoy great flexibility in their scale, design and modes of learning. 
The major vehicle for non-qualification education in Shanghai is the community. Community education, which is the term now commonly used, embraces a number of characteristics:

- Community education are largely provided by voluntary bodies organised among volunteers from the local community. There is crossfertilisation of expertise among the inhabitants of the community.

- Community education itself is a process of mobilisation of local resources. It is a process of "self-entertainment, self-education and self-management". Some of the local communities have consolidated the existing programmes and formed local institutions for adult learning.

- Community education is often integrated with other local facilities such as libraries, gymnasiums, clubs, cultural centres and even night clubs. Community education has become a focal point for all kinds of educational activities outside formal education.

Education for the elderly, in its institutionalised form, is a new-comer in the scene. The major actor of education for the aged is the University for the Elderly. In 1997, there were four major Universities of for the Elderly in Shanghai. They operate through over 1000 centres across the city. Such centres are seen as branches of the Universities managed by local communities at different levels. The total student enrolment in the four Universities for the Elderly around 100,000.

A crude estimation reveals that there are over 80 programmes in the University of the Elderly. They include art, health, domestic science and languages. They have to cater for diverse expectations from students with enormous range of experiences.

Universities for the Elderly survive on three sources of incomes: government subsidy, community or enterprise sponsorship, and student fees. Student fees are usually small. Unlike education for other ages, education for the elderly is admittedly regarded as a welfare as well as education. The overall objective is to make lives after retirement meaningful.

All these new developments are not unique to Shanghai. Similar endeavours are common in other major cities with similar trends of economic and social development. Nevertheless, Shanghai presents the most comprehensive and most comprehensive picture among all.

\section{Concluding and Looking Ahead}

Lifelong learning is not a foreign concept to the Chinese. However, learning in ancient societies are often recognised only in the formal sense by success in the 
civil examinations. Thus, success in lifelong learning is only a reward to the few who thrive in the public examination. In the first 20 years of the socialist Republic, adult education has been confined to preparation or upgrading of manpower as required by the national manpower plan. A large number of people were then given the second opportunity after they have left the formal education system, but not at their own choices. At the first years of the open economy, there is an explosion of needs for continuous education, which is a reflection of the flexible labour market, but is therefore still confined to learning for certification. It is only in the past few years that adults began to participate in education as a matter of leisure and as a way of realising a meaningful life.

One could easily admit that the change in China from socialist to market economy is spectacular. However, it may take some time for one to discern the far-reaching implications of such an economic change to the society at large. Elsewhere, there is discussion about the change among the younger generation in their perceptions of individuals vis-à-vis the state as is reflected in their choice of future career (Cheng, 1994). In this paper, we have seen the change among the working population as is reflected in their aspiration and conception of lifelong education. All these demonstrate change in the entire generation of people. Such a change is fundamental. The vast country is undergoing fundamental change.

However, it is interesting to observe the role of culture in such a process of change. On the one hand, culture plays a positive role in re-confirming the values of education. The Chinese people require little for motivation for education, formal or nonformal, schooling or lifelong. Culture therefore plays a positive role in the reforms. However, the result of such reforms do not always re-assure the traditional values of culture. The developments in lifelong education, for example, have demonstrated the emergence of individual needs and non-incentive motivations for education. There is clear deviation from the tradition aims of education for social mobility or collective objectives.. Education is given a new meaning.

\section{Reference}

Biggs, J.B. (1996) “Western misperceptions of the Confucian-heritage learning culture". In D.A. Watkins \& J.B. Biggs (eds.) The Chinese learner: Cultural, psychological and contextual influences. Hong Kong/Melbourne: Comparative Education Centre/Australian Council for Educational Research. 45-68.

Cheng, K.M. (1994) "Young adults in a changing socialist society: Postcompulsory education in China". Comparative Education, 30(1), 63-74. 
Jin, X. and Gu, X. (1998) Lifelong education in China: A case study of Shanghai. Working Paper, Institute for Research in Adult Education. Shanghai: Shanghai Academy of Educational Research. (Mimeograph)

Liu, H.F. (1996) Keju: Kaoshi de jiaoyu shijiao. (Civil examinations: Education perspectives on examination). Wuhan: Hubei Educational Publishers.

Liu, Y.J. (1993) (eds) Book of major educational events in China, 1949-1990. Hangzhou: Zhejiang Educational Press.

State Council (1988) "Provisional regulations for the Self-Study Higher Education Examinations". In F. Yin (ed.) Planning and administration of higher adult education: A manual. Shanghai: Baijia Publishers, 64-71.

State Education Commission (1987) "Decision on reform and development in adult education". In F. Yin (ed.) Planning and administration of higher adult education: A manual. Shanghai: Baijia Publishers. 25-34.

State Education Commission (1984) Achievement of education in China: Statistics 1949-1983). Beijing: People's Education Press.

State Education Commission (1986) Achievement of education in China: Statistics 1980-1985). Beijing: People's Education Press.

State Education Commission (1991) Achievement of education in China: Statistics 1986-1990). Beijing: People's Education Press.

State Education Commission (1997) Educational statistics yearbook of China. Beijing: People's Education Press.

State Education Commission (1998) Essential statistics of education in China. Beijing: Author. 